\title{
Personal Explorations in the Study of Race and Ethnic Relations
}

\author{
Marguerite V. Marín \\ Gonzaga University \\ marin@gonzaga.edu
}

\begin{abstract}
Many have discussed the inherent problems in teaching race and ethnic relations courses. Students often come to class with preconceived ideas about their social world, and a range of feelings and experiences including confusion, biases, and misconceptions. Therefore, significant barriers to learning exist before the first day of class. To address these challenges, I developed a six-step teaching strategy where students could thoughtfully discuss and collaborate on group projects covering emotionally charged subjects in a non-threatening environment. In doing so, I organized my course, Race and Ethnic Relations, around the students' use of family histories. Students, working in small groups, placed seemingly personal family stories within the broader structures of American race and ethnic relations. Students explored the structural basis of race and ethnic relations through concept-driven assessments of their family histories. The use of personalized family data allowed students to feel at ease discussing difficult topics. This essay includes qualitative data from student projects and their reflections on the effectiveness of this assignment. Student reflections revealed their relative comfort in holding discussions and presenting information on sensitive and uncomfortable topics.
\end{abstract}

Keywords: Student-centered learning, student collaboration, race and ethnic relations, and family histories

\section{Introduction}

Problems encountered in teaching race and ethnic relations courses have been well documented. Haltinner (2014), identifies how students "talk past each other," because they often approach discussions of racial inequality with rigidly set ideas. According to Parrillo (2014) states that students may be reluctant to talk about racial and ethnic disparities because they do not want to offend other students, or, they do not want others to think, they, themselves are racists. Crosby, (2012) reports that students' resistance to the subject rests on their discovery and discussion of unpleasant facts and blatant injustices. In particular, white students often resist ideas of privilege due to their place in the racial and ethnic hierarchy of U. S. society (Chaisson 2004). As such, class discussions and lecture material may generate emotional and potentially antagonistic reactions (Roberts \& Smith, 2002; Wahl, Perez, Deegan, Sanchez, \& Applegate, 2000). Adams, Bell, \& Griffin, (2007) further state that since problematic situations may arise, it is imperative that instructors establish supportive class environments where students can hold discussions about race and ethnic inequality with relative comfort and ease.

Thus, instructors must anticipate that students often come to class with preconceived ideas about race and ethnic inequality, ranging from confusion to misconceptions and stereotypic biases (Springer, 2014; Bohme \& Oka, 2007; Fritschner, 2001; Goldsmith, 2006). 
Often these misunderstandings are compounded by the student's failure to grasp the structural basis of racial and ethnic inequalities. Many students often fail to recognize that racial and ethnic disparities stem from past and as well as present societal arrangements (Mueller, 2012). Thus, many students view racial and ethnic inequalities as the result of individual flaws rather than due to the structural characteristics of society. As a result, significant barriers to learning exist on the first day of class.

To address these challenges, I developed a teaching strategy emphasizing the role that social structures have played and continue to play in race and ethnic inequalities. In doing so, I modified the Team-Based Learning (TBL) approach first developed by Larry Michaelsen (Michaelsen, L. K., Knight A.B. and Fink L.D., 2004), which enabled my students to discuss potentially charged topics thoughtfully and collaborate on group projects in a comfortable learning environment. The TBL method emphasizes outside classroom preparation by students, and in-class group work promoting student learning and accountability. My modifications to the standard TBL structure encouraged students to engage in non-threatening, personalized discussions of race and ethnic relations. Listening to and discussing family stories, some of which were painful experiences, enabled students to openly acknowledge and critically address their ideas about race and ethnic minority groups. Working in teams, students placed what appeared at first glance to be bits of personal family history into the broader context of U.S. life, and their study of race and ethnic relations.

Therefore, with their family experiences and histories as a point of reference, students familiarized themselves with each other, held substantive small group discussions, produced group projects and class presentations, and participated in follow-up class discussions covering diverse and controversial themes. Anonymous student assessments conducted at the end of the semester revealed that most students could hold conversations with relative ease about systemic inequality and other contentious topics. What follows is a description of the course, the students' group work and projects, and student assessments of their coursework. Although I have taught this course many times and assigned the student project each time, examples of student work and student assessments of their work are examples taken from my class taught during fall 2014.

\section{A Little Background: The Setting and the Course}

I teach in a private, mid-size Jesuit university that attracts predominately affluent and white middle-class students. Class sizes are relatively small; about 25-30 students typically enroll in my class. My course on race and ethnic relations is one of several upper division sociology courses. Junior class standing is its only prerequisite. By the end of the semester, students are familiar with the principle terms, concepts and theories within the study of race and ethnic relations. Specifically, students will leave my course with the knowledge of (1) the nature of U.S. race and ethnic relations; (2) the institutional and structural basis of inequality among U.S. racial and ethnic groups; and (3) social changes that have produced greater racial and ethnic equality. Thus, with the use of sociological concepts, I challenge my students to understand how and why patterns of race and ethnic inequality continue to persist, to develop a deeper understanding and respect for diversity, and to identify possible solutions to bring about greater equality. Student assignments, group work, and discussions are organized to address these topics.

Journal of the Scholarship of Teaching and Learning, Vol. 18, No. 3, September 2018. josotl.indiana.edu 
When I began teaching the course during the late 1990s, my class enrollment typically consisted of sociology majors. It was also during these years, that the University instituted a social justice core requirement, paralleling the actions of many colleges and universities across the nation (Downey, \& Torrecilha, 1994). My course was subsequently selected by the College of Arts and Sciences to fulfill this new requirement. However, the social justice designation fundamentally altered the type of student attracted to the class. Not only were many students non-majors, but the social justice designation began to attract students who were not necessarily familiar with sociology, nor particularly interested in it, and some were a little apprehensive about the study of race and ethnic relations. My teaching strategy emerged as I struggled to engage students with a diverse range of interests in the subject.

\section{The Family History Project}

Social science research has repeatedly documented that most Americans continue to enthusiastically believe in the promise of meritocracy and the American Dream. In fact, according to the Pew Research Center (2007), Americans continue to view themselves, not the structural forces of society as determinants of achievement and success in life. Kohut and Dimock (2013), tracking American values over a twenty-five span, conclude that despite economic struggles Americans, on the whole, continue to believe that hard work, and sole reliance "ultimately pay off.” McNamee and Miller (2013) state that, “...Americans tend to look first to the characteristics of individuals to explain what happens to them" (10). Further, they point out that many Americans view failure as resulting from the lack of motivation and poor decision-making rather than the result of structural inequities. Thus, many students, as products of a society that promotes the ethos of individualism, come to class with preconceived ideas about success and failure, believing that personal rather than societal factors explain socioeconomic advancement. Consequently, teaching about race and ethnic inequality can become very challenging for the instructor since students may have little understanding of how social structure guides, and influences social behavior.

Considering that many students enrolled in my course are non-sociology majors, during the first few days of class, I introduce students to the sociological perspective. Therefore, I highlight how social structures and the social context influences an individual's set of ideas, beliefs, attitudes, and behavior. Once I am confident students have grasped key sociological ideas, particularly how social structure patterns relationships between individuals, groups, and institutions, I move on to the basic concepts and topics within the study of race and ethnic relations. My intent throughout the course is to demonstrate how societal forces have channeled social behavior and guided the course of U. S. race and ethnic relations. With an understanding of sociological concepts, students are in the position to document, analyze, and place their family experiences within their broader social contexts, both past, and present. The students' use of their family data serves as an invaluable tool in their study of race and ethnic relations. Students soon develop a stake in the project because they are personally connected to the data.

On the first day of the semester, I inform my students about the family history project. I assign the family history project during the second week of classes. Student progress centers on researching how race or ethnicity influenced their family members' life chances, and how societal forces have guided these experiences. For most students, the personal focus of the assignment sparks immediate interest in the project; however, some students approach the 
assignment cautiously, and a few others with hesitancy. To assist with their projects, I provide students with a list of research themes to consider. (See Appendix 1 for class assignment and list of themes.) The students' method of research is loosely structured around the life history method (Denzin, 2009), which allows the researcher, in this case, the student, to tell the story of the lives of others in a narrative form. Students generate their data by interviewing select family members. Gathering family data in this manner enabled students to both personalize and time analyze their family histories within the context of larger social structures; it enabled students to link family members' behavior, opportunities, and decision-making to particular social and historical eras. Thus, with the use of interview data (and family memorabilia such letters and photos) students utilized their insider perspectives to document past generational experiences and uncover how these circumstances were molded and guided by societal forces.

\section{Collaborative and Team-Based Learning.}

Teaching a course that primarily attracted non-sociology majors with a diverse range of interests in the topic of race and ethnic relations, I realized I had obstacles to overcome. Many students approached my class with preconceived ideas and misgivings, and apprehension about the study of race and ethnicity. Therefore, in my efforts to galvanize student engagement and encourage openness to the topic, I introduced collaborative learning strategies into my course design and student assignments.

The benefits of collaborative group work are many (Yamane, 2006; Bain, 2004; Rau \& Heyl 1990; Petonito, 1991). Working collectively in small groups enables students to pool their resources, receive and process feedback, encourages creativity and motivation, and aids students in mastering the course concepts (Twila \& Hunzicker, 2013). Collaborative strategies not only assist students in the learning process but, at the same time, students become better communicators and listeners (Jones and Jones, 2008).

Therefore, once I introduced collaborative and team-based learning to my students, they were poised to thoughtfully discuss and analyze their family data with their group members. For instance, working within their teams, one student shared family data highlighting 1950s practices of employment discrimination. Armed with class reading material and their knowledge of the discriminatory practices of the era, students became engaged with the sociological perspective as they moved beyond the individual experiences revealed in their family data, by linking and understanding inequality as a direct result of institutional practices of a particular time and place, such as the existence of a "dual wage" system. As students continued their group work, they were able to recognize and discuss the role of structural inequalities with greater ease and confidence.

\section{Organization and Group Work: Personal Explorations in the Study of Race and Ethnic Relations}

The key to my overall strategy is student preparation completed outside of class with several follow-up sessions of in-class work, as emphasized by the Team-Based Learning (TBL) approach (Michaelsen, Knight and Fink, 2004). In brief, the purpose of team-based learning is to move away from the traditional lecture style format to that of a direct application of class material by students working in teams during class time. Thus, rather than merely learning the material via class lectures, students utilize class time applying course material to various 
assignments or problems. TBL consists of about 5-7 teams. The teams are assigned class material they must complete before class. During the first-class meeting, to assure preparedness for the student's in-class teamwork, each student must take an assessment test evaluating their preparation for the team's in-class assignment.

My approach varies from TBL in a significant way. Rather than testing students on their work "readiness" or assimilation of class material, preceding their in-class group work, I require students to submit to me their preliminary family research. The data students generate serve as preparation for their team-based work. Group work consists of their data analysis, organizing panel presentations, and identifying follow-up questions for discussion during the next class session. What follows is a description of my six-step team-based strategy:

\begin{tabular}{|l|l|}
\hline $\begin{array}{l}\text { Step One: } \\
\text { Instructor introduces family } \\
\text { history project. }\end{array}$ & $\begin{array}{l}\text { Step Two: } \\
\text { Student submit brief essay on } \\
\text { conceptual themes emerging from } \\
\text { their family data. }\end{array}$ \\
$\begin{array}{l}\text { Students submit their preliminary } \\
\text { research within a few weeks. }\end{array}$ & $\begin{array}{l}\text { Step Four: } \\
\text { Working with their teams: } \\
\text { a. Students discuss conceptual } \\
\text { themes presented in essays. }\end{array}$ \\
$\begin{array}{l}\text { Based on student conceptual } \\
\text { themes, instructor organizes } \\
\text { collaborative groups. }\end{array}$ & $\begin{array}{l}\text { b. Students share individual family } \\
\text { data with group members. }\end{array}$ \\
& $\begin{array}{l}\text { c. Students utilize sociological } \\
\text { concepts to analysis family } \\
\text { members' opportunities and life } \\
\text { choices. }\end{array}$ \\
& $\begin{array}{l}\text { Step Six: } \\
\text { Student groups prepare follow-up } \\
\text { questions and lead discussion } \\
\text { during the next class session. }\end{array}$ \\
\hline $\begin{array}{l}\text { Step Five: } \\
\text { ftudents present their group's } \\
\text { class. }\end{array}$ & \\
\hline
\end{tabular}

\section{Figure 1: Step-By-Step Instructions for Personal Explorations in the Study of Race and Ethnic Relations.}

Step one. During the sixth week of the semester, I required students to submit their preliminary research. Although rudimentary, the students' data revealed family experiences concerning racial and ethnic conflict, cultural assimilation, ethnic identities, and educational and employment opportunities. Many students provided narratives regarding the ordeals of a particular family member. Others identified the impact of a transformative event for a specific family member. A few students wrote about their personal experiences. Some 
students indicated they knew little about their family background. I utilized the student data (detailed or not) to organize the class into teams working on similar conceptual topics.

Step two. To aid student efficiency, I instructed students to write a short essay on the concepts that best explained their family member experiences. (I returned their essays within a few days.) In some cases, I assisted students in identifying ideas for their analysis. The students' essays provided the necessary preparation for their in-class group discussions.

Step three. I organize students into five teams working on similar conceptual topics. Group size ranged from four to five students. The students' collaborative work in this step consisted of examining their team member's family data with specific sociological concepts or theories in mind.

Step four. With their family data in hand, within a sequence of three class sessions, students discussed their conceptual topics and assisted each other with their data analysis. Working with their teams, students highlighted their family members' opportunities and life choices, and any problematic situations their family members encountered. During the last group session, I directed students to outline the social factors that shaped their family member's experiences, most notably access to educational or economic opportunities. To aid the students' in-class group work, I moved from one group to another, acting more as a facilitator rather than the instructor, fielding any questions or concerns posed by the students. Also, during these group sessions, students were able to address any misconceptions about race and ethnicity. Students taught each other, received feedback and refined their work with the assistance of their teammates.

Step Five. A prominent aspect of the students collaborative learning was sharing their group data with the class as a whole. Mid-way through the semester, working with their groups, students presented their family data to the class in PowerPoint format. With the use of PowerPoints, students were also able to share family pictures and other family documents. One class meeting was devoted to each of the panel presentations.

Step Six. To ensure thematic continuity from class to class, I required that each student team prepare a list of panel-related discussion points which students introduced and discussed during the following class session.

\section{Student Panel Presentations and Follow-up Discussion Topics.}

During the group process (steps three and four) students were able to discuss and time clarify course material as the teams analyzed their groups' family data. The next phase (step five) of the students' team-based work was to present their data analysis to the class in the form of a panel presentation. Students began their panel presentations about the eighth week of the semester. With limited guidance, each group managed an entire class period. During the 50minute class period, I allocated time in the following manner: 25 minutes for panel presentations, 15-minutes for class discussion and the remaining 10 minutes were set aside for each student team to generate follow-up discussion topics for the next class session (step six). For purposes of this paper, I selected the most descriptive student panel data. What follows are brief segments of five student panel presentations and subsequent discussion topics produced by my students, fall semester, 2014. The students' data focused on five themes: (1) conflict and inequality; (2) cultural assimilation; (3) ethnic ties and identities; (4) identities of children of mixed ancestry; and (5) the structures of opportunity. 
Students teaching each other is the cornerstone of team-based learning. My students began this process by working with their respective groups analyzing their data and addressing any difficulties they may have had with the course material. As I identified in step five, students continued teaching each other, but in a panel presentation format. In preparing for their panel presentations, the teams identified sociological concepts they considered most relevant to their data analysis. Since this was a significant component of the students' in-class work, I facilitated the process by providing the teams with immediate feedback offering suggestions and responding to any questions the group members raised about their data and related sociological concepts.

The first team presented family experiences of conflict and inequality. The panelists shared family data highlighting the suppression of minority cultures and economic exploitation. Many of these themes were consistent with conflict theory. This sociological perspective explains social inequality as resulting from the unequal distribution of social resources, social status, power and privilege maintained by dominant groups. Thus, the powerful are in the position to structure society to their benefit. The panelists began their discussion by identifying some of the circumstances giving rise to dominant and subordinate groups. The students' material, emphasized stratified cultural and economic systems. The lead presenter, Laura, noted that racial or ethnic stratified systems are likely to occur when one group dominates the other and exerts its power and control over the subordinated group. Laura supported her statements by referring to her grandmother's experiences following the United States' colonization of Hawaii:

By this time, Hawaiians were a conquered people.

In school, they were forced to speak English and dress

how they dressed [western attire]. The schools

were completely westernized--my grandmother

refused to go to school.

Other presenters continued the themes of the panel by highlighting racially stratified workplaces and the resulting economic inequities. For example, Mary referred to the working conditions her grandmother endured as a garment worker in 1960s Los Angeles, stating:

She worked hard, in extreme heat with few breaks.

She was always tired. Her supervisor was always

rushing the workers; her supervisor even timed

the minutes she took in the bathroom. The workers

were reprimanded if they spoke Spanish, most of

the workers were Mexican or Mexican American,

the supervisors, were Anglos [white Americans].

The above quote identified the harsh working conditions of the garment factory, and it also highlighted the factory supervisor's control over the cultural expressions of the workers. 
Nick, the next presenter, referred to the racial and ethnic hierarchy at his grandfather's place of work, a Chicago meatpacking factory during the 1950s:

There were a lot of different people at the plant, many different nationalities working together, but doing different jobs. There were Italians, Polish, Puerto Ricans, and African Americans; but the supervisors, according to my grandfather were all the 'white bread' type.

While this student was not aware of specific wage differentials, given the era, he observed, that "...factory owners increased their profits through unregulated wages and discriminatory practices."

The students continued by presenting additional examples of economic exploitation and powerlessness, and the suppression of minority cultures. These themes laid the groundwork for the following day's class discussion. Following the panel, as part of their collaborative teamwork, I instructed the student groups to take some time to identify a few topics to be discussed during the next class meeting.

During the following class period, the student groups resumed their examination of the social and economic conditions of powerless people. One student referring to the class readings commented on past practices of a two or multi-tiered wage system where one or more groups of workers receive lower wages than another. The discussion leader continued by identifying industries that continue to be stratified by race and ethnicity and the history behind these social and economic patterns. Class discussions also concerned the possibilities of increasing the minimum wage to that of a living wage, unregulated labor practices and the current wage differentials that exist between racial, ethnic and gender groups. The class hour concluded with a discussion on the possibilities of lobbying for and enacting fair labor legislation.

\section{Panel Number 2: Cultural Assimilation.}

The following week the second group of panelists presented it family data to the class. The team focused on the concept of assimilation. The students introduced their topic by identifying the role of conformity and accommodation within racial and ethnic hierarchies. The panelists' presented data calling attention to the varying processes of assimilation. The panelists briefly discussed the tenets of functionalist social theory by noting the pivotal role assimilation plays in maintaining societal stability. Most of the students' data consisted of themes related to cultural assimilation; they highlighted how the norms and values of the dominant society shaped their family members' patterns of accommodation by indicating that immigrants must abandon their cultural ways to gain acceptance by the dominant group. Megan, the lead panelists, by commenting on the cultural choices made by her greatgrandparents, she stated: 
My great-grandparents did retain part of the culture by speaking their native language to each other, reading Swedish newspapers. However, they chose not to pass on the Swedish language to their nine children. They knew the community would not accept their children unless they took on the ways of the dominant group.

Megan further stated that her great-grandparents followed the trails of previous Swedish immigrants in the upper Midwestern United States. Her great-grandparents became prosperous dairy farmers by providing products and services to the local community. Megan also acknowledged that her great-grandparents' social networks and ties to their Swedish extended family, neighbors, and friends facilitated their transition to their new life.

Victoria, sharing entirely different circumstances, also commented on the role of language and cultural assimilation in her family's history:

My grandmother recalled that her eldest daughter, came home from school in tears one day because the other kids had made fun of the way she spoke, and this was not a one-day occurrence, her classmates often ridiculed her. My aunt spoke English well, but with a heavy accent, from then on, my grandmother refused to teach the rest of her children Spanish. English became the only language spoken in the house, and it was the only language my mother learned.

Victoria continued by stating that the humiliation her aunt experienced was not limited to the actions of her peers. School authorities also punished her aunt and other students if they spoke Spanish in class or on the school playground.

Another student of Iranian decent commented on her parent's attempts to assimilate following the Twin Tower attacks on September 11, 2001:

After 9/11, my parents never felt comfortable; it is only now getting better. They both worked hard to speak English with no accent. They dressed as Americans did...they wanted to blend in as much as possible because they were Middle Eastern. We talked several times about the violent attacks on people [in the U.S.] just because they looked Arab or had brown skin.

As the above suggests, the assimilation process is not harmonious and conflict-free as functionalist social theory suggests. The student presenters noted that the deliberate choices made by their family members were guided by attempts to lessen the anguish and fear associated with being "the other." While these students noted conscious decisions by their family members as the result of disparaging treatment, these examples also accentuated the range of experiences and consequences. Their family experiences also represented the inter- 
ethnic relations of a particular time and place. As the above quotes suggest, throughout U.S. history, cultural assimilation has occurred on a large scale, such as that experienced by ethnic groups of European origins. However, racial and ethnic minority groups have differed in the pace and their overall acceptance by the larger society and subjected to varying types of discriminatory treatment. As the above quotes suggest, the acceptance or rejection of varying racial and ethnic groups involves patterns of assimilation stemming from the resistance by the dominant group to accept those that are different.

The student teams generated follow-up questions concerning the degree and variation of the assimilation process by diverse cultural groups. During the subsequent class session, one student the advantages of assimilation, but questioned: "at what cost?" The student recognized that for some, assimilation involves the loss of culture, language and possible family ties. In a related theme, another student asked, "why are some groups more likely to assimilate than others?" Other student acknowledged that the range of cultural and physical differences affects acceptance by the dominant society. Overall, students discussed the normative cultural patterns of a community, in directing the course of assimilation.

\section{Panel Number 3: Ethnic Ties and Identities.}

During the third week of presentations, the panelists discussed the social basis of ethnic identities. The presenters began by recognizing that although racial and ethnic identities are very personal, they are framed and guided by the social structure of society--societal norms and values. The first panelist began the discussion by calling attention to the variability of ethnic ties and identities, stating that "... assimilation occurs, but, at the same time many people continue to identify with their ethnic heritage to a lesser or greater extent". The panelists continued by identifying several factors as sources of ethnic group identities. For example, one student revealed ethnic pride and identification with her family's participation in a historical event:

The men of my mother's family were in charge of putting together a petition to gain Hawaii's independence from United States' control. It is so exciting to see your family's name on these documents because their main purpose was to keep Hawaiian culture alive and regain control of land...it is an important part of our history.

A student of German American ancestry identified ties to language and family as a source of ethnic identity:

My grandmother stopped speaking German when she was in grade school. When my sister and I started learning German in high school, she began speaking it again. It created a special bond with my grandmother, and it connected me to my German culture as well.

A student of Mexican American ancestry stated: 
When I was young, I never thought about my ethnic background until I attended high school. I was insulted because of the color of my skin. They would make fun of my name and even the food I ate. Looking back, it was at this point that I began to take pride in my ancestry.

During the following class session, as a way of initiating the class discussion, I asked the class a simple, yet complicated question: what influences the development of ethnic identities? One student, referring to the data presented during the panel discussion, responded by reiterating the role of shame and reticule as forces in identity formation. Other students discussed the fluid nature of ethnic identities and how social factors, such as socialization, ties to specific communities, and reactions by of the broader community may influence ethnic identities. Thus, the student discussion indicated that how individuals view and define themselves which can be a source of pride or discomfort, profoundly affect one's racial and ethnic identity.

Panel Number 4: Children of Mixed Racial Ancestry.

The themes of the fourth week of panel topics were more personal than the previous presentations. The presenters discussed social situations they experienced as children of mixed racial ancestry. The first panelist introduced the group topic with a short discussion of census material referring to the growing numbers of Americans of mixed background. However, the overall theme of the panel addressed uncomfortable situations the panelists experienced as children. For example, Lisa, a student of Korean and Irish ancestry, stated that her schoolmates frequently reminded her that she was different:

'Hey, what are you?' If I had a personal list of frequently asked questions, this would be at the top of the list. Typically, I would pretend not to understand the question. Inevitably though, I ended up explaining my background. I often thought to myself, 'why does it matter so much?'

Another student of white and African American ancestry stated that at times she was mocked because of her "in-between" status:

Sometimes I felt that I was not accepted anywhere, white kids did not like me because I was dark and black kids would say something like, 'you're not like us, you have a white mother'.

The next presenter, Adrian, of Jamaican and Canadian background, stated that he was often "given the third degree" because he never identified himself as African American: 
My mother is from Kingston, Jamaica and my father is Canadian. Inever identify as an African American, but, because of my skin color, people assume I'm African American. Some people ask if I'm ashamed of my heritage because I always say I'm Jamaican and Canadian when people ask—and they always do.

The themes of this panel varied from the previous presentations, the panelists discussed circumstances they directly experienced, but the presenters grounded their examples with references to specific studies. During the next class session, a student volunteered to start the discussion by addressing the topic of marginalization and acceptance by one's peers. To stimulate further conversation, I asked the class to consider the formal and informal customs of categorizing people by "rigidly" defined racial categories and the blatant inconsistencies of these practices. One student responded to my question by commenting on how social constructions can influence an individual's perceptions of diverse groups. Another student referred to the disdain that many groups have faced, but are now part of mainstream society, and how others continue to be marginalized and viewed in stereotypic ways. Another student concluded the discussion by revisiting the panelists' reference to the U.S. Census Bureau's inconsistent and ever-changing racial and ethnic categories.

Panel Number 5: The Structures of Opportunity.

During the fifth and final week of presentations, as a way of concluding their projects, and teamwork, Iasked all students to review their data and examine any difficulties their family members experienced and to identify how their family members overcame these circumstances. My primary objective in this section of their project was to encourage students to analyze the existing structural conditions that influenced their family's opportunities rather than focus on individual motivations. Considering the American ethos of individualism, a belief system that is hard to escape, I encouraged students to identify the structural conditions that influenced their family members' life chances. This aspect of their team-based learning enabled students to place their family experiences within the racial and ethnic hierarchies of U.S. society.

A few students documented in rich detail the circumstances that influenced their family member's life chances. I chose these students to present their data to the class. During the final presentation, the panelists identified several political and economic factors that channeled their family member's opportunities. For example, William, the lead presenter stated:

My family can trace their roots to Lincoln...they came to the United States about the time Abraham Lincoln signed the Homestead Act of 1862. My relatives were farmers without land; they were able to get 'a piece of the pie' early on because of the Homestead Act. They settled in Minnesota and North Dakota...after the Native populations of the area were forced onto reservations. 
Lawrence, an African American student, commented on his great-grandparents increased opportunities resulting from a more open labor system:

In the 1920s my great-grandparents and their five kids moved to Ohio from Mississippi to work in the meat-packing plants. They moved north for better jobs. They still lived in segregated communities. But, my grandmother remembers having better housing and more of the basics of life.

Another student, Grace, commented on the opportunities her grandfather gained access to as a World War II veteran:

My grandfather only completed the third grade, so he really could not benefit from the G.I. Bill's educational benefits. But, he and my grandmother were able to buy their first home with a low-interest loan provided by the G.I. Bill.

The above statements set the tone for the following class meeting. During the studentled discussion, one student reintroduced the theme of social structures as forces in emerging opportunities. However, she also noted that "what helps one person can disable another," identifying institutionalized discrimination that benefits the dominant group at the expense of minority groups. Another student identified human agency, specifically civil rights movements as significant forces in promoting social change. Another student discussed specific federal government responses to racial and ethnic inequality and demands by activists for increased educational and economic opportunities. As such, students concluded their discussion with the theme of hope, rather than that of despair (Moulder,1997).

\section{Student Outcomes and Reflections.}

The study of race and ethnic relations is central to sociological instruction. In my course, I challenge students to understand how and why patterns of race and ethnic inequality continue and to seek possible solutions to bring about greater equality. However, achieving my goals can be difficult for several reasons. Many students come to class with preconceived ideas about race and ethnic relations (Goldsmith, 2006); and many students may resist the class itself, fearful of courses that address race and ethnic inequality (Crosby, 2012). Therefore, it is imperative that instructors establish supportive classroom environments that promote thoughtful discussions about troubling and uncomfortable topics.

The primary objective of my students' team-based assignments was to assist students in understanding and discussing difficult and potentially charged topics through with the use of their personal connections to the study of race and ethnic relations - their family histories. At the end of the semester, I asked students to anonymously comment on their group work and group interactions, and the overall value of their family history project. According to the student reflections, most indicated that they derived value from this assignment. Student comments suggested that they had the opportunity to speak about race and ethnic relations with 
relative ease. Student comments also indicated that, in general, they appreciated the opportunity to take ownership of their learning by directly applying the class concepts to their family experiences. Also, familiarity with their family data and class concepts provided students with confidence to engage in meaningful sociological discussions. For example, as one student wrote:

This class made me realize that I could learn about sociology by studying my own family. We were not just memorizing; we were applying concepts to real situations.

The following comments indicated that the nature of their group work and the topics discussed, helped students carry on honest and open discussions. For example, another student wrote:

Everyone was talking about their background...at first, I was quiet. There were two African American students in my group. As we got to know each other, talking about our families became almost natural. The black students shared stories about their family members and how they dealt with blatant discrimination. These were things I never even thought about.

However, a few students commented on their initial difficulty with the group discussion, one student stated:

It was tough for someone who is not a minority, but the family examples from class connected all of us to the material. I was able to see how segregation of the past continues to affect us today, especially, for African Americans. I never realized current neighborhood patterns are an offshoot of the past.

Another student commented:

At first, I felt uncomfortable. I did not want to say something that would be taken the wrong way. I did not want to insult anyone. All my friends are white, so talking about, and trying to understand prejudice and discrimination in this way was really new to me.

One student expressed fears that her team members would judge her because of her family's prejudices:

\section{I didn't want to say anything about my family,}


especially my grandfather. I didn't want my group to think I was a racist. But as the class got into the readings I learned, I think I always knew, his attitudes and behavior were influenced by the society where he lived...that's what I talked about, how we learn prejudice. Someone else in my group shared similar experiences.

The following statements are from a student who, at the outset, struggled with her project:

I did not think I would learn anything, but I was wrong. By studying my family history, I can understand my life as well as the lives of my ancestors. It helped me to recognize the importance of history and the importance of respecting diversity. It has allowed me to be more conscientious of the world around me, and the people in it.

One of the most problematic topics to teach, and for students to recognize, is the U.S. system of structural advantages (Wooddell \& Henry 2005). When students recognize and understand the existence of systemic advantages, they begin to call into question ideas about equal opportunity and whether it exists for all members of U.S. society. As stated in their reflections, several students were able to identify direct connections between their family members' opportunities and the structural patterns of social reproduction and white privilege. The following student comments about meritocracy were particularly revealing. One student wrote:

My grandfather could go to college on the G.I. Bill. I thought everyone had this chance, and I now know this is not the case.

The student continued:

When my dad was college age, he was able to attend the same college my grandfather did because my grandfather was an alumnus of a traditionally all-white college. I now see how this is part of white privilege.

Another student continued with the theme of structural advantages:

I never thought about the importance of the land that my ancestors got years ago. It's still in my family. My father inherited it, and my family has lived very comfortably because of it. I never fully recognized how the past influences the opportunities we have today.

Another student commented on the value contradictions of American culture:

When I read the text, and talked about it with 
my group, I saw how society does influence

what paths we take, especially race. It is interesting

because we are always told that everyone has an

equal opportunity, obviously, this isn't true.

However, a few students revealed their continued belief in meritocracy--that success or failure in life is the direct result of individual motivation and hard work, and not necessarily due to systemic inequality. For example, one student wrote:

I've always been told that everyone lives by the same rules. So, listening to stories about the struggles some of my group members talked about was tough for me to identify with.

Another student stated:

I understand what the readings are saying, and what my group members talked about, but I've met a lot of successful ethnic minority people. So, I think people can make it, even when life is tough.

The last two set of comments indicate that for some students I was not successful in conveying the role that social structure plays in one's life chances. It appears that for some students they were unable to place opportunities within the broader social context and acknowledge that social factors guide and influence life circumstances. Comments like these also impressed upon me the strength of the American individualistic ethos and how it continues to sustain particular views of the social world, especially judgments individual achievements or failures.

\section{Conclusion}

The most important lessons I have gleaned from my pedagogic approach is that students must be provided with avenues to exert control over their learning in a supportive environment. Students must have opportunities to directly connect their class assignments with their lived experiences, coupled with a classroom setting promoting trust and respect. As students discussed complex course material, my approach allowed students to breathe life into course material by making "abstract concepts real" (Steele, 2003), and with the use of their family experiences, I helped my students understand and directly apply the sociological perspective to their lives.

However, while my approach reaped many benefits, a few students from the outset of the semester talked with me in private about their concerns with their projects. For example, one student I vividly recall mentioned to me in private that he had no interest in researching his father's family history. The student continued by stating that he was not interested because his father has "always had it easy." My immediate response was: Why do you think this is so? He responded by indicating that his father's race and upper-class opportunities, particularly inheritance, played a significant role in his father's successes. Following this student's initial resistance, we brainstormed for a few minutes. We were subsequently able to identify a topic he was excited about and interested in researching. The student decided to 
focus on the ascribed characteristics of race and class, and how they factored into his father's life and the lives of other family members. Thus, after a rocky start, this student completed an insightful project on his family's advantages of wealth, access to social and cultural capital, and privileges associated with race. Other students expressed varying degrees of apprehension, some of their fears concerned practical issues such as time constraints and the potential failure in retrieving information about their family members, and the personal nature of the project. More worrisome concerns focused on the discussion of controversial topics. However, as the evidence in this essay suggests, for most students, these misgivings waned as students began working with their teams and assisting each other with their family data and course material.

Structuring my class to reach students through my team approach provided several advantages. Students developed their sociological skills through the process of personalizing their study of race and ethnic relations. Although the project was a requirement, each student determined what family information they would share with their teams, and what they would present to the class. Consequently, with the assistance of their group members, students could place seemingly personal and historical bits of information within the broader social structures of American race and ethnic relations. For many white students, this allowed them to move beyond stories describing hard work by recognizing that many opportunities were available to their family members because of systemic privileges. It also encouraged students to understand how societal beliefs about race, and opportunities or lack of opportunities, are guided by the social, economic and political structures of society. This assignment emphasized the basic premise of the sociological perspective. With the use of the students' family histories, students connected their "biography and history" (Mills 1959) to make sense out of their family's life chances and the structural patterns of race and ethnic relations.

This assignment was much more than a term project. The course syllabus, text, lectures and discussions all served as tools in guiding the students' research, group projects, and presentations. Class material guided the students' data collection and their data analysis. Once armed with their intellectual tools, and working with their teams, students developed a framework to understand the complexity of race and ethnic relations through the use of personal family explorations. Their family experiences became the bridge to class material, and their sociological analysis of race and ethnic relations. This project enabled students to place their families' life chances within the structure of U.S. society; students linked sociological concepts with their family experiences, data they were personally connected to. As Mueller (2011) states, “... students are more apt to consider where they fit in the 'larger web’ of systemic racial realities when studying their own histories” (185).

While my team-based strategy has worked well with my classes of about 25 students, instructors can adapt it to larger classes with some modifications. For classes with about fifty students, teaching assistants may help manage the students' group work. However, the greater number of students in a classroom might necessitate more selectivity of panel themes and more significant time constraints placed on the student presentations. My approach can also be useful for most classes that address other societal disparities, such as social class, and gender inequality, topics that many students continue to find troublesome. Student-generated data and the out of class preparation could be tailored to these topics and continue to serve as the basis for their team-based learning. In this manner, students could continue to make personal connections to broader social structures and at the same time explore and discuss uncomfortable topics in a supportive classroom setting. 
The overarching benefit of my approach is student accountability to their group members and classmates through their teamwork. Students assisted each other with the analysis of data and the personalization of abstract concepts. Through this project, students took responsibility for their learning by organizing and coordinating their teams' data and use of sociological concepts and presentation of their research to the class. By examining their group member's data, students were in the position to hold in-depth discussions about race and ethnic inequality. Student reflections revealed their relative comfort in holding conversations and presenting information on emotional, troubling and challenging topics. Having open talks about race and ethnic inequality in a comfortable and intellectual setting is paramount if we are to move toward greater social equality, particularly considering the current politics of hate, the anti-immigrant atmosphere, and the repeated acts of bigotry occurring within any U.S. communities.

\section{Acknowledgements}

I would like to thank the anonymous reviewers for their time and recommendations for improving the manuscript. Also, I would like to thank Edward Vacha for his support of this project.

\section{Appendix}

\section{Appendix 1: Project Assignment: Your Family History}

Part One: This family history project is designed to assist you in your understanding of the sociological perspective. As you explore your family history, you will be making connections between the experiences of your family and its social context. The central focus of your paper will be to document the role that race or ethnicity played in their family's history. As you explore your family history, you will analyze your family's experiences with the use of relevant sociological concepts. Specifically, you will research how race or ethnicity influenced their family members' opportunities, and how their family experiences were affected by the broader social and historical context.

Students will generate their data by interviewing select family members. Your method of research will be the "life history" method. This research method will help you to personalize and at the same time develop an understanding of the structural basis of race and ethnic relations. It will enable you to see the relationship between biography (your life or your family member's life) and the social structure (society).

To assist with you with your projects, you may select a few research themes from the following list:

1. Describe the immigrant origins of your family.

2. Discuss any ethnic or cultural traditions your family continues to practice.

3. Discuss the role of language in your family history (English language acquisition, bilingualism, language patterns of children, etc.).

4. Discuss the role of race in friendship/dating/marriage patterns of family members or yourself. 
5. Identify the life chances of your family members (such as education, economic, housing/neighborhood opportunities). Did family/friendship/community networks play a role in gaining access to these opportunities?

6. Did family members reveal any difficulties as they described the above experiences? If so, how were family members able to overcome th 5 challenges they encountered?

The completed paper will be due at the end of the semester. The page length is approximately 10-12 pages with references (primary and secondary sources) and bibliography.

Part Two: You will work in small groups and assist each other with their family analysis. I will group you with other students working on similar sociological concepts. You will begin your teamwork by writing a short essay on a sociological concept or theory that best describes your family data and sharing these thoughts with your group. As part of your group work, you will also share parts of your family history with the class. Sharing your data with the class will take the form of an informal panel presentation. (Don't worry family skeletons will go unmentioned!). Working with your group, you will collectively decide what to present to the class.

Part Three: Following the panel presentation, working in teams, students will come up with a list of panel related topics which students will discuss during the next class session.

\section{References}

Adams, M., Bell, L.A. and Griffin, P. (2007). Teaching for Diversity and Social Justice. New York: Routledge.

Bain, K. (2004). What the Best College Teachers Do. Cambridge, MA: Harvard University Press.

Bohmer, S. and Oka, K. (2007). Teaching Affirmative Action: An Opportunity to Apply, Integrate, and Reinforce Sociological Concepts. Teaching Sociology 35(4), 334-49.

Chaisson, R. L. (2004). A Crack in the Door: Critical Race Theory in Practice at a Predominantly White Institution. Teaching Sociology 32(3), 345-57.

Crosby, D. B. (2012). Meeting the Challenge: Teaching Sensitive Subject Matter. The Journal of Effective Teaching 12(2), 91-104.

Downey, D. J. and Torrecilha, R. (1994). Sociology or Race and Ethnicity: Strategies for Comparative Multicultural Courses. Teaching Sociology 22(3), 237-47.

Denzin, N. and Lincoln (2002). The Qualitative Inquiry Reader. Thousand Oaks, CA: Sage Publications. 
Fritschner, L. M. (2001). Lessons about Race in Introductory Sociology. Teaching Sociology 29(1), 110-15.

Goldsmith, P. A. (2006). Learning to Understand Inequality and Diversity: Getting Students Past Ideologies. Teaching Sociology 34(3), 263-77.

Haltinner, K. (2014). Teaching Race and Anti-Racism in Contemporary America. New York, NY: Springer Publishing Company.

Hollander, J. A. (2002). Learning to Discuss: Strategies for Improving the Quality of Class Discussion. Teaching Sociology 30(3), 317-27.

Kohut, A. and Dimock. M. (2013). Resilient American Values: Optimism in an Era of Growing Inequality and Economic Difficulty. Washington, DC: Council on Foreign Relations.

Jones, K. and Jones, J.L. (2008). Making Cooperative Learning Work in the College Classroom: An Application of the 'Five Pillars' of cooperative Learning to Post-Secondary Instruction. Journal of Effective Teaching, 8(2), 61-76.

Lukowiak, T. and Hunzicker, J. (2013). Understanding How and Why College Students Engage in Learning. Journal of Effective Teaching, 13 (1), 44-63.

McNamee, S. J. and Miller, R. K. (2013) The Meritocracy Myth. Boulder: Rowman and Littlefield.

Michaelsen L. K., Knight, A. B. and Fink L. D. (2004). Team-Based Learning: A Transformative Use of Small Groups in College Teaching. Sterling, VA: Stylus.

Moulder, F. V. ( 1 997). Teaching About Race and Ethnicity: A Message of Despair or a Message of Hope. Teaching Sociology 25(2), 120-27.

Mueller, J. (2012). Tracing Family, Teaching Race: Critical Race Pedagogy in Millennia/Sociology Classroom. Teaching Sociology 41(2), 172-87.

Roberts, A. and Smith K. (2002). Managing Emotions in the College Classroom: The Cultural Diversity Course as an Example. Teaching Sociology 30(3), 291-301.

Rau, W. and Heyl, B. S. (1990). Humanizing the College Classroom: Collaborative Learning and Social Organization Among Students. Teaching Sociology 18(2), 141-55

Parrillo, Vincent N. 2014. Strangers to These Shores. Boston: Allyn and Bacon.

Petonito, G. (1991). Fostering Peer Learning in the College Classroom.” Teaching Sociology 19 (2), 498-501. 
Marín

Pew Research Center. 2007. Optimism About Black Progress Declines: Blacks See Growing Values Between Poor and Middle Class. Washington, DC: Pew Research Center.

Poll, C. (1995). More Than Reading Books: Using Oral Histories in Courses in Race and Ethnicity. Teaching Sociology 25(2), 145-49.

Steele, T. (2003). Sex, Culture, and Linguistic Relativity: Making Abstract Concepts Real. Teaching Sociology 31(2), 212-20.

Springer, J. T. (2014). What's Post Racial Discourse got to do with it? Obama and the Implications for Multiculturalism in College Classrooms. Journal of the Scholarship of Teaching and Learning 14(3), 1-15

Wahl, A., Perez E., Deegan M. J., Sanchez, T. and Applegate C. ( 2000). The Controversial Classroom: Institutional Resource and Pedagogical Strategies for a Race Relations Course. Teaching Sociology 28(4), 316-32.

Wooddell, G. and Henry, J. (2005). The Advantage of a Focus on Advantage: A Note on Teaching Minority Groups. Teaching Sociology 33 (3), 301-309.

Yamane, D. (2006). Course Preparation Assignments: A Strategy for Creating a Discussion-Based Courses. Teaching Sociology 34(3), 236-48. 